\title{
Study on cleavage fracture probability-load curves of ferritic steel 20MnMoNi55 by using the new local approach model
}

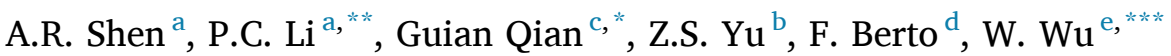 \\ ${ }^{a}$ School of Mechanical and Automotive Engineering, Shanghai University of Engineering Science, Shanghai, 201620, China \\ ${ }^{\mathrm{b}}$ School of Materials Engineering, Shanghai University of Engineering Science, Shanghai, 201620, China \\ c State Key Laboratory of Nonlinear Mechanics (LNM), Institute of Mechanics, Chinese Academy of Sciences, Beijing, 100190, China \\ ${ }^{\mathrm{d}}$ Department of Mechanical and Industrial Engineering, Norwegian University of Science and Technology (NTNU), Richard Birkelands vei 2b, 7491, Trondheim, Norway \\ e Institute of Advanced Structure Technology, Beijing Institute of Technology, Beijing, 100081, China
}

\section{A R T I C L E I N F O}

\section{Keywords:}

Cleavage fracture probability

Ferritic steel

NLAM

Predicted load

\begin{abstract}
A B S T R A C T
In this paper, the new local approach model (NLAM) is first adopted to predict the cleavage fracture probabilityload curves of notched round bar tensile specimens of ferritic steel $20 \mathrm{MnMoNi} 55$ at the temperatures of $123 \mathrm{~K}$ and $223 \mathrm{~K}$. Then, based on the obtained curve, the probability density function, and the extreme value theorem of function, two significant cleavage fracture probabilities are proposed. Finally, the proposed probabilities are employed to predict the load which is most likely to cause cleavage fracture of $20 \mathrm{MnMoNi55}$ steel. The results show that when the value of cleavage fracture probability is $45.29 \%$, the corresponding predicted load is basically equal to the average fracture load of the specimens. Besides, the load corresponding to the cleavage fracture probability of $59.7 \%$ is the most likely one to induce cleavage fracture of the structure.
\end{abstract}

\section{Introduction}

Ferritic steels are commonly used to make nuclear pressure vessels. Due to the hostile service environment, ferritic steels are prone to cleavage fracture [1,2], which will lead to many serious accidents [3]. In order to further study cleavage fracture, French Beremin group proposed a local approach model (LAM) of cleavage fracture [4], which was called the Beremin model [5]. It has been adopted by the famous specification for assessment of structural integrity with defects-R6 [6]. From the perspective of micromechanics, the Beremin model quantitatively gives the relationship between the external load of the structure and the cleavage fracture probability. The cleavage fracture probability is expressed as a two-parameter Weibull distribution based on the weakest-link theory [7-9]:

$P=1-\exp \left[-\left(\frac{\sigma_{W}}{\sigma_{0}}\right)^{m}\right]$

where $P$ is the cleavage fracture probability, $m$ and $\sigma_{0}$ are the characteristic parameters of the local approach (LA) of cleavage fracture. $m$ denotes the Weibull modulus, $\sigma_{0}$ denotes the Weibull scale parameter. The Weibull stress $\sigma_{W}$ is the driving stress of cleavage fracture and is defined as follows:

$\sigma_{W}=\left(\int_{V_{p l}} \sigma_{1}^{m} \cdot d V / V_{0}\right)^{1 / m}$

where $V_{p l}$ is the volume of the fracture process zone for calculating $\sigma_{W}$. The element of the fracture process zone satisfies $\sigma_{1} \geq \lambda \sigma_{y s}(\lambda \geq 1)$ [10], where $\sigma_{y s}$ is the yield stress, $\lambda$ is the threshold coefficient in the fracture process zone. $\sigma_{1}$ is the maximum principal stress of the element, $d V$ is the volume of an element, $V_{0}$ denotes the reference volume reflecting the microstructure of the material. $\sigma_{W}$ is generally obtained by post-processing program of finite element analysis. When calculating the values of $m$ and $\sigma_{0}$, it is required to have a set of measured cleavage fracture experimental data with a certain algorithm, such as the classical Minami calibration method [11]. It is worth noting that the Beremin model is still immature so far. Although $m$ and $\sigma_{0}$ were considered as material constants when the Beremin model was first established, subsequent studies showed that the parameters of the Beremin model vary

\footnotetext{
* Corresponding author.

$* *$ Corresponding author.

$* * *$ Corresponding author.

E-mail addresses: wiselee18@163.com (P.C. Li), qianguian@imech.ac.cn (G. Qian), Wuwenwang2014@163.com (W. Wu).
} 


\begin{tabular}{|c|c|}
\hline \multicolumn{2}{|c|}{ Nomenclature } \\
\hline$d V$ & differential volume $\left(\mathrm{mm}^{3}\right)$ \\
\hline LA & local approach \\
\hline LAM & local approach model \\
\hline$m$ & Weibull modulus \\
\hline NLAM & new local approach model \\
\hline$P$ & cleavage fracture probability \\
\hline $\bar{P}$ & average cleavage fracture probability \\
\hline \multicolumn{2}{|c|}{$d_{P}\left(\sigma_{W, \text { new }}\right)$ density function of cleavage fracture probability } \\
\hline$V_{p l}$ & volume of the fracture process zone $\left(\mathrm{mm}^{3}\right)$ \\
\hline$\lambda$ & threshold coefficient in the fracture process zone \\
\hline$\sigma_{0}$ & Weibull scale parameter (MPa) \\
\hline$\sigma_{1}$ & maximum principal stress of the element (MPa) \\
\hline$\sigma_{1,0}$ & $\begin{array}{l}\text { maximum principal stress of the element entering the } \\
\text { initial yield (MPa) }\end{array}$ \\
\hline$\sigma_{t h}$ & threshold stress (MPa) \\
\hline$\sigma_{W}$ & Weibull stress (MPa) \\
\hline$\sigma_{W-\min }$ & threshold Weibull stress (MPa) \\
\hline$\sigma_{W, \text { new }}$ & newly defined Weibull stress (MPa) \\
\hline $\bar{\sigma}_{W, \text { new }}$ & average Weibull stress (MPa) \\
\hline$\sigma_{y s}$ & yield stress (MPa) \\
\hline
\end{tabular}

greatly and even contradict each other (e.g. Refs. [12-15]). To address the problem above, scholars studied and revised the Beremin model. For example, Bakker et al. [16], introduced threshold stress $\sigma_{\text {th }}$ in Eq. (1). Similarly, Gao et al. [17], introduced threshold Weibull stress $\sigma_{W-\min }$ in Eq. (1). However, most of these revisions are lack of deep theoretical proofs. Aiming at this problem, Lei [18], grasped the characteristic that plastic yield is the prerequisite of cleavage fracture and then proposed a NLAM of cleavage fracture based on the Beremin model. The new model mainly modifies the solution formula of the Weibull stress:

$P=1-\exp \left[-\left(\frac{\sigma_{W, \text { new }}}{\sigma_{0}}\right)^{m}\right]$

where $\sigma_{W, \text { new }}$ is the newly defined Weibull stress, and its expression is as follows:

$\sigma_{W, \text { new }}=\left[\int_{V_{p l}}\left(\sigma_{1}-\sigma_{1,0}\right)^{m} \frac{d V}{V_{0}}\right]^{1 / m}$

with $\sigma_{1,0}$ is the maximum principal stress of the element entering the initial yield. As described in detail in Lei, [19]; when plastic deformation is a prerequisite for cleavage fracture, there must be threshold stress equal to $\sigma_{1,0}$. It is traditionally considered that the threshold stress of cleavage fracture is a constant, which is a wrong concept. Because the cleavage fracture is premised on plastic yield, while for a given material (microstructure unchanged), the yield itself is still affected by the stress state (geometric shape of the sample), temperature, loading rate and so on. So $\sigma_{1,0}$ is recommended as threshold stress, it is the value of maximum principal stress calculated according to the Mises yield criterion but not a fixed value. Note that the main difference between the new model and the Beremin model lies in the introduction of $\sigma_{1,0}$. As mentioned in Qian et al. [3], and Lei, [19]; in the Beremin model, $\sigma_{W}$ is calculated by $\sigma_{1}$. According to Eqs. (1) and (2), it can be seen that when the cleavage fracture does not occur, the minimum value of the failure probability is non-zero. Clearly, this doesn't make sense in terms of both probability theory and physics. In other words, the minimum probability of non-fracture must be zero. Conversely, in the new model, $\left(\sigma_{1}-\sigma_{1,0}\right)$ is used to replace $\sigma_{1}$ in the original Beremin model. In this way, it can not only guarantee that the prerequisite for cleavage fracture of any element is plastic yield, but also ensure that the formula conforms to the normalization of probability theory [20]. Eq. (3) can be transformed into the following form:

$\operatorname{LnLn}(1 /(1-P))=m \operatorname{Ln}\left(\sigma_{W, \text { new }}\right)-m \operatorname{Ln}\left(\sigma_{0}\right)$

The main function of Eq. (5) is to calibrate the two Weibull parameters $\left(m, \sigma_{0}\right)$. For such linear equation, there has been a relatively perfect calibration method [21]. When the values of Weibull parameters are known, the cleavage fracture probability can be calculated via Eq. (3). Since the LA can be used to predict the cleavage fracture probability of a structure (such as piping and pressure vessel steel) under a given load [22], the load corresponding to any cleavage fracture probability can be obtained from the cleavage fracture probability-load curve of a fracture test sample. In the case of fracture toughness test specimen, the fracture toughness corresponding to a certain load can be obtained by the relations between fracture toughness and external load, so as to predict the fracture toughness value of the material at any cleavage fracture probability. Then the questions arise, which fracture probability corresponding to load is more practical, and what is the physical meaning of a specific probability and its corresponding load? These questions need to be further studied. To tackle the above problems, Hui et al. [23], investigated the low temperature fracture notched bar specimens based on the Beremin model and proposed a significant cleavage fracture probability. On the basis of the above work, this study aims to employ the NLAM to predict the cleavage fracture probability-load curves of a certain structure under two different temperatures, and derive the formula of the cleavage fracture probability model to predict the external load which is most likely to cause the cleavage fracture of $20 \mathrm{MnMoNi55}$ steel.

\section{Predicted cleavage fracture probability-load curves of 20MnMoNi55 steel}

In this work, notched round bar tensile specimens of 20MnMoNi55 steel are used and the dimension parameters of the specimens are shown in Fig. 1 (all units are in mm). 20MnMoNi55 steel is a kind of pressure vessel steel that contains the following trace elements: C $0.21 \%, \mathrm{Si}$ $0.21 \%$, Mn $1.3 \%$, S 0.001\%, P 0.009\%, Ni 0.68\%, Cr 0.05\%, Mo 0.494\%, $\mathrm{V} 0.01 \%, \mathrm{Al} 0.029 \%$ and $\mathrm{Fe}$ balance. The mechanical properties are given in Table 1 and the true stress-plastic strain curves at $123 \mathrm{~K}$ and $223 \mathrm{~K}$ are shown in Fig. 2 [20,24,25].

It is noteworthy that the present study is a follow-up work of the research presented in Shen et al., [24]. According to the previous calibration results of Weibull parameters of 20MnMoNi55 steel, it can be seen that the two parameters are temperature-independent, and the values of $m$ of $20 \mathrm{MnMoNi55}$ steel at both $123 \mathrm{~K}$ and $223 \mathrm{~K}$ are all about 11. Readers can refer to Chakraborti et al., [25]; for more details about the method and process used to calibrate the Weibull parameters in the NLAM, here it will not be enumerated. Thus, in this work, the results of Weibull parameters $\left(m, \sigma_{0}\right)$ obtained by Shen et al. [24], $(11.16,1743.6)$ at $123 \mathrm{~K}$ and $(10.581,1662.73)$ at $223 \mathrm{~K}$ ) are directly used to calculate the cleavage fracture probability in combination with Eq. (3). It can be seen from Eq. (3) that a Weibull stress corresponds to a failure probability, whereas, Eq. (4) shows that the calculation of Weibull stress depends on $\sigma_{1}$, while $\sigma_{1}$ depends on external load. Thereby, a Weibull stress corresponds to an external load. Hence, the relationship curve between the cleavage fracture probability and the external load can be obtained. Consequently, the predicted cleavage fracture probability-load curves of the notched round bar tensile specimen of the 20MnMoNi55 at two temperatures above are displayed in Fig. 3.

It is worth mentioning that Fig. 3 has two functions. One is to predict the failure probability of the structure under a given external load. The other is to predict the external load subjected by the structure under a certain failure probability. Although the cleavage fracture probability corresponding to the load can be determined through Fig. 3, yet, as stated in Section 1, it remains a challenging issue to choose reasonably 


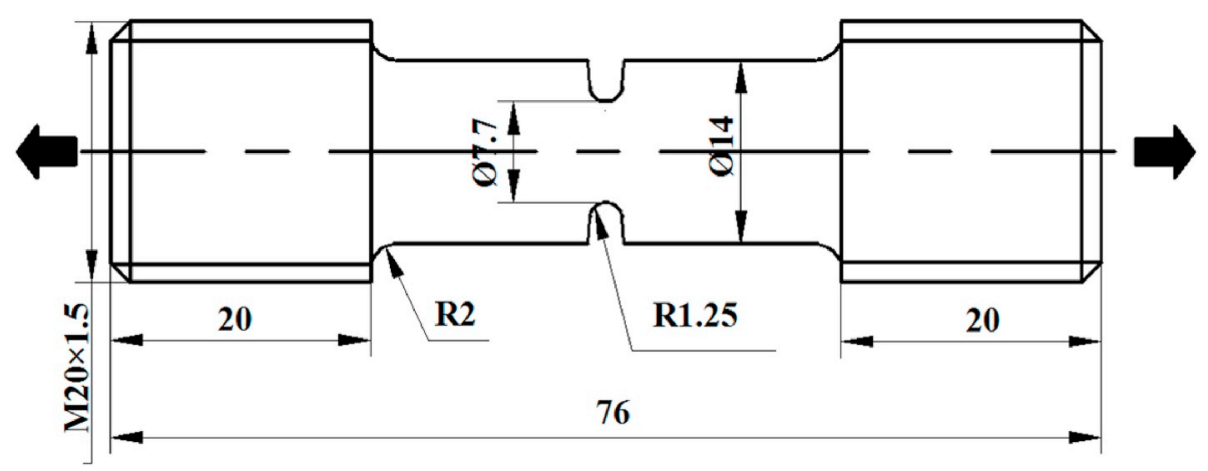

Fig. 1. Notched round bar used for tensile tests [24].

Table 1

Material properties of 20MnMoNi55 steel.

\begin{tabular}{ll}
\hline Young's modulus $E$ & $200 \mathrm{GPa}$ \\
Poisson's ratio $\nu$ & 0.3 \\
Temperature & Yield stress $\sigma_{y s}$ \\
$123 \mathrm{~K}$ & $685 \mathrm{MPa}$ \\
$223 \mathrm{~K}$ & $537 \mathrm{MPa}$ \\
\hline
\end{tabular}

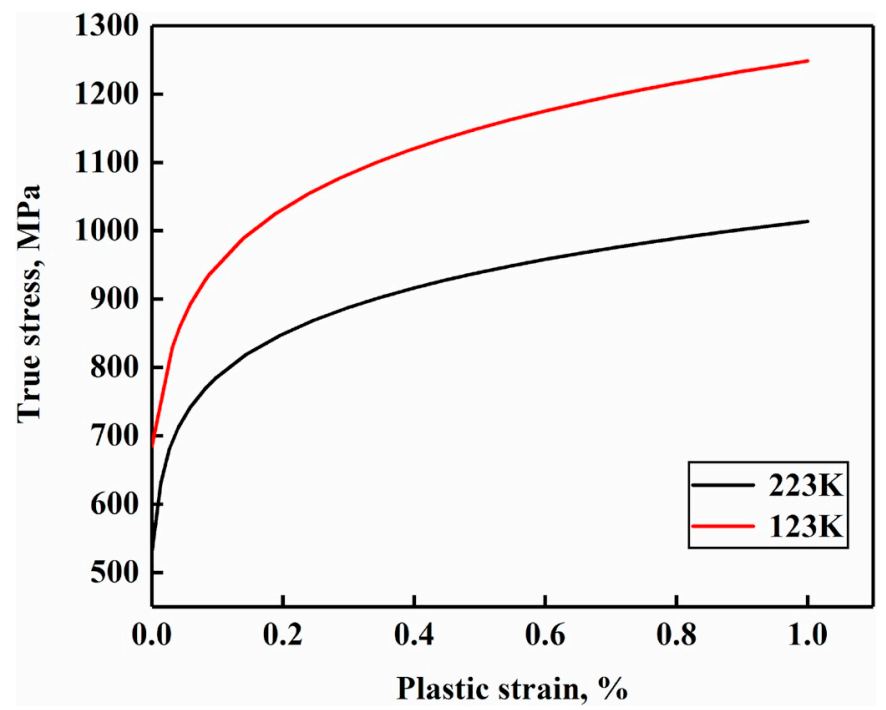

Fig. 2. True stress-plastic strain curves of $20 \mathrm{MnMoNi55}$ steel at $123 \mathrm{~K}$ and $223 \mathrm{~K}$.

which probability corresponding to the load to conduct the study. For this reason, based on the significant cleavage fracture probability model presented by Hui et al., [23]; two significant cleavage fracture probabilities are proposed by using the NLAM. Under multiaxial loading, the fracture probability is not yet calculated [26-28].

\section{Two significant cleavage fracture probabilities}

\subsection{The first significant cleavage fracture probability}

As previously mentioned, Eq. (3) gives the relationship between the cleavage fracture probability $P$ and the Weibull stress $\sigma_{W, \text { new }}$. Taking the derivative of both sides of Eq. (3) with respect to $\sigma_{W \text {,new }}$ leads to

$d_{P}\left(\sigma_{W, \text { new }}\right)=\frac{m \sigma_{W, \text { new }}^{m-1}}{\sigma_{0}^{m}} \exp \left(-\left(\frac{\sigma_{W, \text { new }}}{\sigma_{0}}\right)^{m}\right)$

where $d_{P}\left(\sigma_{W, \text { new }}\right)$ is the density function of cleavage fracture probability.

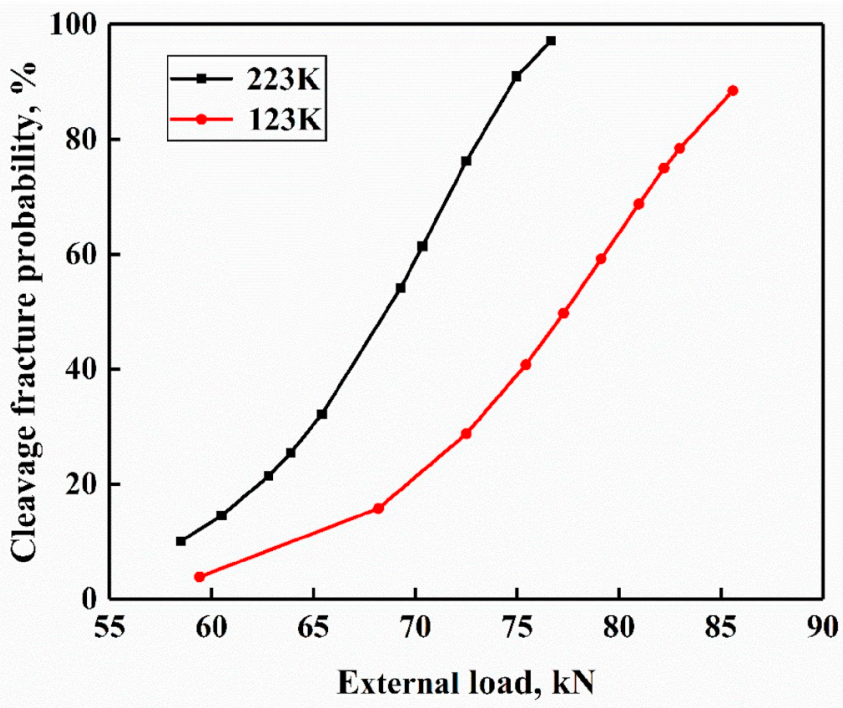

Fig. 3. Predicted cleavage fracture probability-external load curves of notched specimens of $20 \mathrm{MnMoNi55}$ steel at $123 \mathrm{~K}$ and $223 \mathrm{~K}$. (by using the NLAM).

Based on $d_{P}\left(\sigma_{W, \text { new }}\right)$, it is possible to obtain its expectation, that is, the average Weibull stress $\bar{\sigma}_{W, \text { new }}$ as

$$
\begin{aligned}
& \bar{\sigma}_{W, \text { new }}=\int_{0}^{\infty} \sigma_{W, \text { new }} d_{P}\left(\sigma_{W, \text { new }}\right) d \sigma_{W, \text { new }}=\int_{0}^{\infty} \frac{m \sigma_{W, \text { new }}^{m}}{\sigma_{0}^{m}} \exp ( \\
& \left.-\left(\frac{\sigma_{W, \text { new }}}{\sigma_{0}}\right)^{m}\right) d \sigma_{W, \text { new }}
\end{aligned}
$$

To calculate $\bar{\sigma}_{W, \text { new }}$, let us set

$\left(\frac{\sigma_{W, \text { new }}}{\sigma_{0}}\right)^{m}=t$

According to Eq. (8),

$\frac{d \sigma_{W, n e w}}{d t}=\sigma_{0} \cdot \frac{1}{m} \cdot t^{\frac{1}{m}-1}$

Combining Eqs. (7)-(9) produces

$\bar{\sigma}_{W, \text { new }}=\sigma_{0} \int_{0}^{\infty} t^{\frac{1}{m}} \exp ^{(-t)} d t=\sigma_{0} \int_{0}^{\infty} t^{\frac{1}{m}+1-1} \exp ^{(-t)} d t=\sigma_{0} \Gamma\left(\frac{1}{m}+1\right)$

where $\Gamma$ is the Gamma function. Substituting Eq. (10) into Eq. (3) arrives at

$\bar{P}=1-\exp \left(-\left[\Gamma\left(\frac{1}{m}+1\right)\right]^{m}\right)$

From Eq. (11), it can be seen that the average cleavage fracture 
probability $\bar{P}$ is only related to $m$. The relation curve of $\bar{P}$ with respect to $m$ obtained from Eq. (11) is illustrated in Fig. 4.

\subsection{The second significant cleavage fracture probability}

Taking the derivative of Eq. (6) leads to

$\dot{d}_{p}\left(\sigma_{W, \text { new }}\right)=\left[m-1-m\left(\frac{\sigma_{W, \text { new }}}{\sigma_{0}}\right)^{m}\right] \cdot m \frac{\sigma_{W, \text { new }}^{m-2}}{\sigma_{0}^{m}} \exp \left[-\left(\frac{\sigma_{W, \text { new }}}{\sigma_{0}}\right)^{m}\right]$

According to the extreme value theorem of function in calculus, let $d_{p}^{\prime}\left(\sigma_{W, \text { new }}\right)=0$, the extreme value point is obtained as

$\sigma_{W, \text { new }}=\sigma_{0}\left(\frac{m-1}{m}\right)^{\frac{1}{m}}$

Substituting Eq. (13) into Eq. (3) yields

$P=1-\exp \left(\frac{1-m}{m}\right)$

Under the conditions of Eqs. (13) and (14), there is a need for further judging the cleavage fracture probability density $d_{P}\left(\sigma_{W, \text { new }}\right)$ will reach its maximum value or minimum one. To this end, one can take the second derivative of Eq. (6). That is,

$$
\begin{aligned}
& d_{P}^{\prime \prime}\left(\sigma_{W, \text { new }}\right)=\left\{\left(m-1-\left(\frac{\sigma_{W, \text { new }}}{\sigma_{0}}\right)^{m}\right) \cdot\left[m-2-\left(\frac{\sigma_{W, \text { new }}}{\sigma_{0}}\right)^{m}(m-1)\right]\right. \\
& \left.-m^{2}\left(\frac{\sigma_{W, \text { new }}}{\sigma_{0}}\right)^{m}\right\} \cdot \frac{m \sigma_{W, \text { new }}^{m-3}}{\sigma_{0}^{m}} \exp \left[-\left(\frac{\sigma_{W, \text { new }}}{\sigma_{0}}\right)^{m}\right]
\end{aligned}
$$

Recalling Eq. (13) holds true at the extreme value point, equating Eq. (15) with Eq. (13) gives

$d_{P}^{\prime \prime}\left(\sigma_{W, \text { new }}\right)=-\frac{m^{2}(m-1)}{\left(\frac{m-1}{m}\right)^{1 / 3}} \exp \left(\frac{1-m}{m}\right)$

As can be seen from Eq. (16), there is always $d_{p}^{\prime \prime}\left(\sigma_{W, \text { new }}\right)<0$ as long as $m>1$. That is to say, the cleavage fracture probability density will reach the maximum value when the Weibull stress satisfies Eq. (13). In this situation, the corresponding cleavage fracture probability shall obey Eq. (14). On the basis of Eq. (14), the cleavage fracture probability $P$ is plotted against the Weibull modulus $m$ in Fig. 5.

Through Figs. 4 and 5, it can be clearly seen that the relationship curves between $P$ and $m$ in both situations, and then these two

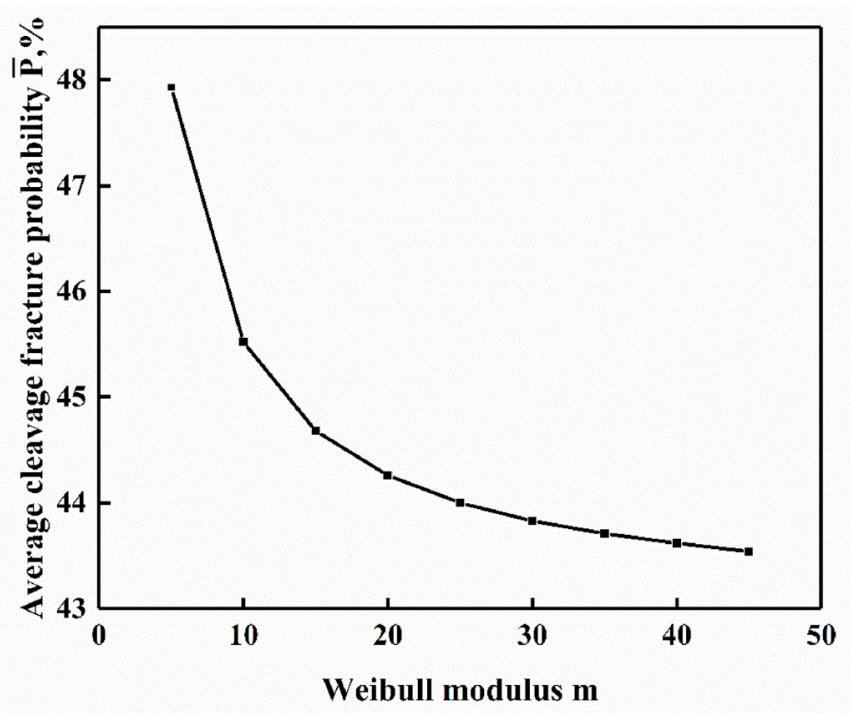

Fig. 4. Average fracture probability $\bar{P}$ versus Weibull modulus $m$. significant cleavage fracture probabilities can be applied to the practical case of 20MnMoNi55 steel in the next section.

\section{Results and discussion}

In Section 2, the curves of predicted cleavage fracture probability versus external loads of $20 \mathrm{MnMoNi55}$ steel at $123 \mathrm{~K}$ and $223 \mathrm{~K}$ are represented in Fig. 3. And two significant cleavage fracture probabilities are shown in Figs. 4 and 5 in Section 3. In this section, it is analyzed in conjunction with Figs. $3-5$, and the obtained results are illustrated in Fig. 6 and Table 2.

As mentioned above, the Weibull modulus of 20MnMoNi55 steel at both two temperatures are all about 11. According to Eq. (11), it is known that the average cleavage fracture probability corresponding to $m=11$ is $45.29 \%$. Then, it can be determined from Fig. 6 that the corresponding predicted load at $123 \mathrm{~K}$ is around $76.2 \mathrm{kN}$ if the cleavage fracture probability is taken as the above average value $45.29 \%$. According to the 10 groups of loads values selected for the finite element simulation at two temperatures in Shen et al., [24]; the average fracture load of the 10 groups is $76.37 \mathrm{kN}$ when the temperature is $123 \mathrm{~K}$. Likewise, as for the case of $223 \mathrm{~K}$ presented in Fig. 6, the corresponding predicted load of $45.29 \%$ cleavage fracture probability is about $67.7 \mathrm{kN}$. This compares favorably with the average experimental fracture load ( $67.49 \mathrm{kN}$ at $223 \mathrm{~K}$ by Ref. [24]. The above results indicate that the corresponding predicted load is almost equal to the average fracture load of the specimens when the cleavage fracture probability is taken as the average value.

Besides, it can be seen from Eq. (14) that the cleavage fracture probability is $59.7 \%$ when $m=11$. This implies that when the density function of cleavage fracture probability reaches maximum, the corresponding cleavage fracture probability is about $59.7 \%$. As a result, the predicted load corresponding to this probability shall be the most likely load to cause cleavage fracture of the structure. As can be seen from Fig. 6, the corresponding predicted load is about $79.1 \mathrm{kN}$ at $123 \mathrm{~K}$, and $70 \mathrm{kN}$ at $223 \mathrm{~K}$ when the cleavage fracture probability is $59.7 \%$. That is to say, when the temperature is $123 \mathrm{~K}, 79.1 \mathrm{kN}$ is the most likely load to cause cleavage fracture in $20 \mathrm{MnMoNi55}$, while, as for $223 \mathrm{~K}, 70 \mathrm{kN}$ is the most likely load to cause cleavage fracture. For the benefit of the readers, the results of predicted loads corresponding to the two significant cleavage fracture probabilities of $20 \mathrm{MnMoNi55}$ steel at two temperatures are summarized in Table 2.

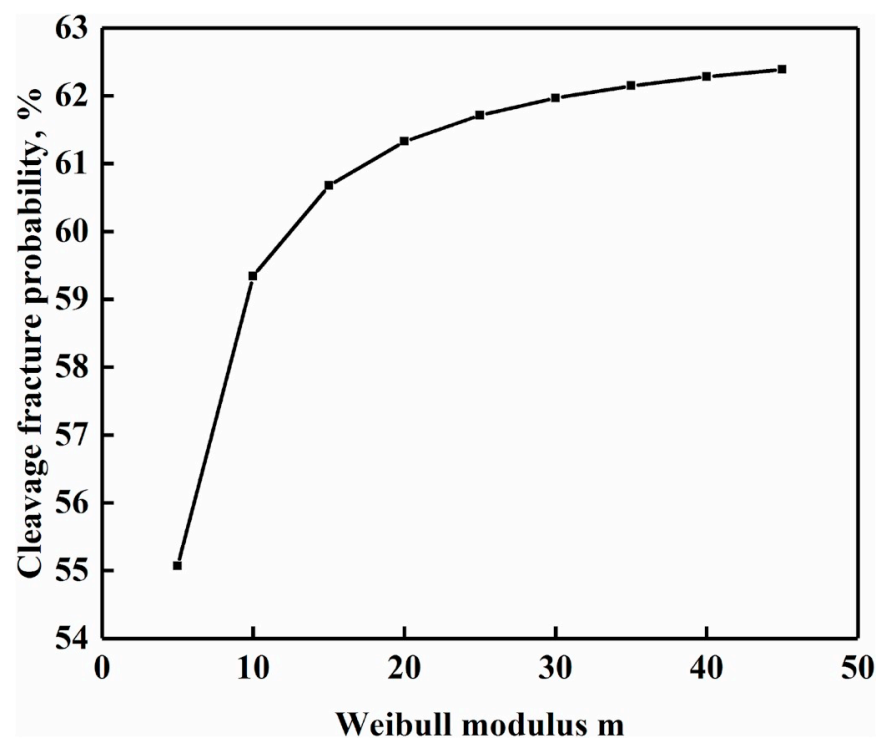

Fig. 5. Cleavage fracture probability $P$ versus Weibull modulus $m$ (when $d_{P}\left(\sigma_{W, \text { new }}\right)$ reaches maximum $)$. 


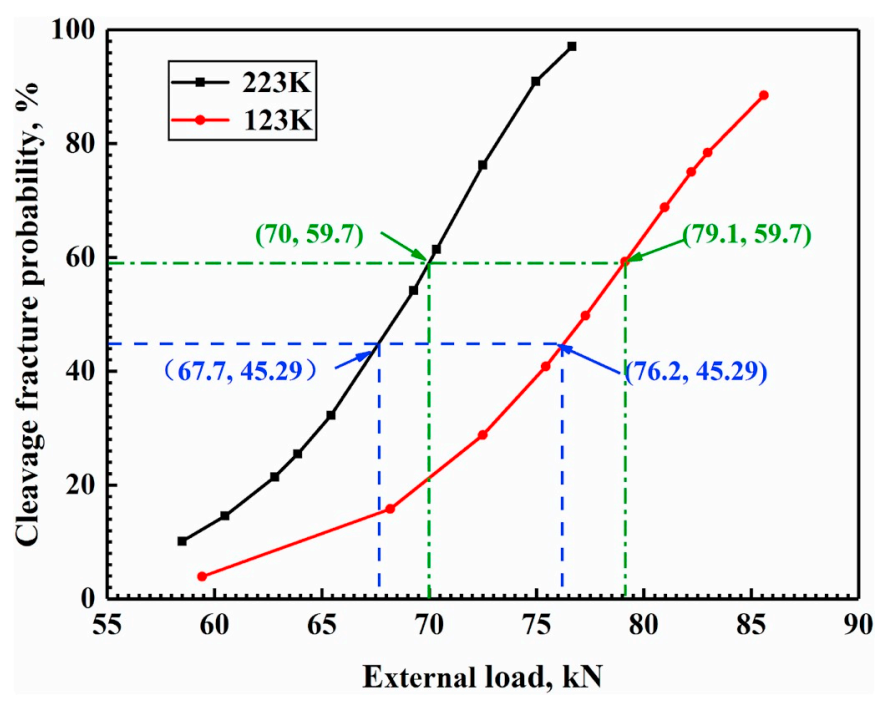

Fig. 6. The predicted loads corresponding to two significant probabilities at two temperatures $(m=11)$.

\section{Table 2}

Loads corresponding to the probabilities of two significant cleavage fractures at two temperatures.

\begin{tabular}{lll}
\hline $\boldsymbol{P}$ & External load $(\mathrm{kN})$ & \\
\cline { 2 - 3 } & $123 \mathrm{~K}$ & $223 \mathrm{~K}$ \\
\hline $\mathbf{5 9 . 7 \%}$ & $\mathbf{7 9 . 1}$ & $\mathbf{7 0}$ \\
$\mathbf{4 5 . 2 9} \%$ & 76.2 & 67.7 \\
\hline
\end{tabular}

\section{Conclusions}

The cleavage fracture probability-load curves of 20MnMoNi55 steel at two temperatures are predicted, and two important cleavage fracture probabilities are proposed. Loads which are most likely to cause cleavage fractures of the structure at two temperatures are predicted. The main conclusions of the present study are summarized as follows:

(1) For $20 \mathrm{MnMoNi55}$ ferric steel, the load corresponding to $45.29 \%$ of the cleavage fracture probability is basically equal to the average fracture load of the specimen.

(2) When the cleavage fracture probability is $59.7 \%$, the corresponding load of this probability is the load which is most likely to cause the cleavage fracture of the structure of $20 \mathrm{MnMoNi} 55$ steel.

(3) At $123 \mathrm{~K}, 79.1 \mathrm{kN}$ is the load most likely to cause cleavage fracture of $20 \mathrm{MnMoNi} 55$ steel, whereas, $70 \mathrm{kN}$ is the load most likely to cause cleavage fracture of $20 \mathrm{MnMoNi} 55$ steel at $223 \mathrm{~K}$.

Note that the application of the two cleavage fracture probability formulae proposed in this work to $20 \mathrm{MnMoNi55}$ is novel, they can also be applicable to other types of ferritic steels.

\section{Acknowledgements}

This work is funded by the Natural Science Foundation of Shanghai (Grant No. 19ZR1421400), the National Natural Science Foundation of China (Grant No. 11872364), and the CAS Pioneer Hundred Talents
Program.

\section{References}

[1] G. Qian, W.S. Lei, L. Peng, Z. Yu, M. Niffenegger, Statistical assessment of notch toughness against cleavage fracture of ferritic steels, Fatigue Fract. Eng. Mater. Struct. 41 (2017) 1-12.

[2] G. Qian, W.S. Lei, Z. Tong, Z. Yu, A statistical model of cleavage fracture toughness of ferritic steel DIN 22NiMoCr37 at different temperatures, Materials 12 (6) (2019) 982.

[3] G. Qian, W.S. Lei, M. Niffenegger, Calibration of a new local approach to cleavage fracture of ferritic steels, Mater. Sci. Eng. A 694 (2017) 10-12.

[4] G. Qian, Y. Cao, M. Niffenegger, Y.J. Chao, W. Wu, Comparison of constraint analyses with global and local approaches under uniaxial and biaxial loadings, Eur. J. Mech. A Solid. 69 (2018) 135-146.

[5] F.M. Beremin, A. Pineau, F. Mudry, et al., A local criterion for cleavage fracture of a nuclear pressure vessel steel, Metall. Trans. A 14 (1983) 2277-2287.

[6] R.A. Ainsworth, R6-Revision 4: Assessment of the Integrity of Structure Containing Defects, Landon: British Energy Generation Ltd, 2000.

[7] W.S. Lei, A statistical model of cleavage fracture in structural steels with power-law distribution of microcrack size, Philos. Mag. Lett. 96 (2016) 101-111.

[8] G. Qian, W.S. Lei, Z. Yu, F. Berto, Statistical size scaling of breakage strength of irregularly-shaped particles, Theor. Appl. Fract. Mech. 102 (2019) 51-58.

[9] G. Qian, W.S. Lei, A statistical model of fatigue failure incorporating effects of specimen size and load amplitude on fatigue life, Philos. Mag. 1 (2019) 37, https:// doi.org/10.1080/14786435.2019.1609707.

[10] C. Ruggieri, R.H. Dodds, A transferability model for brittle fracture including constraint and ductile tearing effects: a probabilistic approach, Int. J. Fract. 79 (1996) 309-340.

[11] F. Minami, Estimation procedure for the Weibull parameters used in the local approach, Int. J. Fract. 54 (1992) 197-210.

[12] P.P. Milella, N. Bonora, On the dependence of the Weibull exponent on geometry and loading conditions and its implications on the fracture toughness probability curve using a local approach criterion, Int. J. Fract. 104 (2000) 71-87.

[13] C.S. Wiesner, M.R. Goldthorpe, The effect of temperature and specimen geometry on the parameters of the "local approach" to cleavage fracture, J. Phys. France 06 (1996) C6-295-C6-304.

[14] J.P. Mathieu, O. Diard, K. Inal, S. Berveiller, Micromechanical modeling of brittle fracture of French RPV steel: a comprehensive study of stress triaxiality effect, in: Proceedings of ASME, 2008 pvp2008-61334.

[15] J.P. Mathieu, K. Inal, S. Berveiller, O. Diard, A micromechanical interpretation of the temperature dependence of Beremin model parameters for French RPV steel, J. Nucl. Mater. 406 (2010) 97-112.

[16] A. Bakker, R.W.J. Koers, Prediction of cleavage fracture events in the brittle-ductile transition region of ferritic steel, in: Schwalbe Blauel (Ed.), Defect Assessment in Components-Fundamentals and Applications, ESIS/EG9. London, 1991.

[17] X. Gao, C. Ruggieri, R.H.D. Jr, Calibration of Weibull stress parameters using fracture toughness data, Int. J. Fract. 92 (1998) 175-200.

[18] W.S. Lei, A cumulative failure probability model for cleavage fracture in ferritic steels, Mech. Mater. 93 (2015) 184-198.

[19] W.S. Lei, A framework for statistical modelling of plastic yielding initiated cleavage fracture of structural steels, Philos. Mag. 96 (2016) 3586-3631.

[20] G. Qian, W.S. Lei, M. Niffenegger, V.F. Gonzálezalbuixech, On the temperature independence of statistical model parameters for cleavage fracture in ferritic steels, Philos. Mag. 98 (2018) 959-1004.

[21] K. Hojo, I. Muroya, A. Brucknerfoit, Fracture toughness transition curve estimation from a notched round bar specimen using the local approach method, Nucl. Eng. Des. 174 (1997) 247-258.

[22] G. Qian, M. Niffenegger, M. Sharabi, N. Lafferty, Effect of non-uniform reactor cooling on fracture and constraint of a reactor pressure vessel, Fatigue Fract. Eng. Mater. Struct. 41 (7) (2018) 1559-1575.

[23] H. Hui, P.N. Li, Study on fracture of notch bars at low temperature with local approach, J. Mech. Eng. 45 (2009) 306-312 (in Chinese).

[24] A.R. Shen, P.C. Li, K.Y. Wang, G. Qian, F. Berto, A simplified method for parameters calibration of the new local approach model for cleavage fracture in a ferritic steel, Theor. Appl. Fract. Mech. 100 (2019) 426-433.

[25] P.C. Chakraborti, A. Kundu, B.K. Dutta, Weibull analysis of low temperature fracture stress data of 20MnMoNi55 and SA333 (Grade 6) steels, Mater. Sci. Eng. A 594 (2014) 89-97.

[26] D. Liao, S.-P. Zhu, G. Qian, Multiaxial fatigue analysis of notched components using combined critical plane and critical distance approach, Int. J. Mech. Sci. 160 (2019) 38-50.

[27] D. Liao, S.-P. Zhu, Energy field intensity approach for notch fatigue analysis, Int. J. Fatigue 127 (2019) 190-202.

[28] S. Xu, S.-P. Zhu, Y. Hao, D. Liao, New strain energy-based critical plane approach for multiaxial fatigue life prediction, J. Strain Anal. Eng. Des. 53 (2018) 719-729. 